\title{
PRODUÇÃO E COMPOSIÇÃO BROMATOLÓGICA DO SORGO (SORGHUM BICOLOR) CULTIVADO SOB DOSES DE NITROGÊNIO
}

\author{
PRODUCTION AND CHEMICAL COMPOSITION OF SORGHUM (SORGHUM BICOLOR) \\ GROWN UNDER NITROGEN LEVELS
}

\author{
Macedo, C.H.O. ${ }^{1 *}$, Santos, E.M. ${ }^{1}$, Da Silva, T.C. ${ }^{2}$, De Andrade, A.P. ${ }^{1}$, Da Silva, D.S. ${ }^{1}$, \\ Da Silva, A.P.G. ${ }^{1}$ e De Oliveira, J.S. ${ }^{1}$
}

1Departamento de Zootecnia. Universidade Federal da Paraíba (UFPB). Areia-PB. Brasil. *chompvhro@hotmail.com

²Departamento de Zootecnia. Universidade Federal de Viçosa (UFV). Viçosa-MG. Brasil.

\section{PalaVRas chaVe AdicionaIs}

Colmo. Lâmina foliar. Matéria seca. Panícula.

\section{RESUMO}

Objetivou-se avaliar a resposta produtiva e a composição bromatológica do sorgo híbrido BR 601 ao incremento da adubação nitrogenada. O delineamento experimental utilizado foi em blocos casualizados com cinco repetições. Os tratamentos foram: 0, 50, 100, 150 e $200 \mathrm{~kg} / \mathrm{ha}$ de $\mathrm{N}$ (sulfato de amônio). A produção variou de forma quadrática ao incremento da adubação nitrogenada, o ponto de máxima para a materia verde foi obtido com 143,19 kg de N/ha (37996 kg/ha) e para matéria seca com 155,67 kg de N/ha (16 275 $\mathrm{kg} / \mathrm{ha}$ ). A produção de lâmina foliar e material morto na planta não diferiu entre os tratamentos. O percentual de colmo na planta diminuiu de forma quadrática até a dose de $100 \mathrm{~kg} / \mathrm{ha}$, o componente panícula aumentou de forma quadrática em $30,96 \%$, o que explica que este componente foi o principal responsável pelo aumento na PMS. O percentual médio de matéria seca da planta variou de $34,84 \%$ no tratamento controle a $38,98 \%$ no tratamento com $200 \mathrm{~kg}$ de N/ha. Os teores de MM diminuíram $(6,41$ a $5,49 \%)$. O teor de PB incrementara linearmente com o aumento nas doses de adubo aplicadas, com variação no teor protéico de 4,99\% a $6,23 \%$, respectivamente nos tratamentos 0 e $200 \mathrm{~kg}$ de N/ha. Os teores de fibra em detergente neutro, fibra em detergente ácido e hemicelulose não diferiram em função da adubação nitrogenada. A adubação nitrogenada aumenta a produção de matéria seca e panícula sem alterar os constituintes fibrosos da planta.

Recibido: 15-3-11. Aceptado: 22-9-11.

\section{AdDitional KEYWORDS}

Stem. Leaf. Dry weight. Panicle.

\section{SUMMARY}

This study evaluated the productive response and chemical composition of sorghum hybrid BR 601 to nitrogen fertilization. The experimental design was randomized blocks with five replications. The treatments were: $0,50,100,150$ and $200 \mathrm{~kg} \mathrm{~N} / \mathrm{ha}$ (ammonium sulfate). There was a quadratic increase of yield with $\mathrm{N}$ fertilization, the higher value was obtained with $143.19 \mathrm{~kg}$ of $\mathrm{N} / \mathrm{ha}$ for fresh matter $(37996 \mathrm{~kg} / \mathrm{ha})$ and with $155.67 \mathrm{~kg}$ of $\mathrm{N} / \mathrm{ha}$ for dry matter $(16275 \mathrm{~kg} / \mathrm{ha})$. The production of leaf and dead material at the plant did not differ between treatments. The percentage of stem in the plant decreased quadratically up to a dose of $100 \mathrm{~kg} / \mathrm{ha}$ and the panicle component increased quadratically to $30,96 \%$. So, this component was the main responsible for increase in DM yield. The average plant dry matter varied from $34.84 \%$ to $38.98 \%$ in the treatment with $200 \mathrm{~kg} \mathrm{~N} / \mathrm{ha}$. The levels of MM decreased (6.41 to $5.49 \%$ ) and crude protein increased linearly (from $4.99 \%$ to $6.23 \%$ ) with increasing doses of $\mathrm{N}$. The levels of neutral detergent fiber, acid detergent fiber and hemicellulose did not differ in relation to nitrogen fertilization. The nitrogen increases the production of dry matter and panicle without changing the fiber constituents of the plant.

\section{INTRODUÇÃO}

A região Nordeste do Brasil e responsável por $(91,4$ e $57,2 \%)$ do rebanho de

Arch. Zootec. 61 (234): 209-216. 2012. 
caprinos e ovinos (IBGE, 2007). Contudo os níveis de produtividade são baixos o que deve-se, principalmente, à forte dependência que os sistemas de produção têm da vegetação nativa da caatinga, fonte alimentar básica, quando não única, dos rebanhos. Nas estações secas, a redução na oferta de forragem é o principal fator determinante do baixo nível de produtividade, portanto, é de importância o plantio de culturas forrageiras anuais no período chuvoso, de forma que possam garantir a suplementação animal na época seca pelo armazenamento do alimento na forma de silagem. Apesar do alto potencial produtivo da cultura de sorgo e da grande disponibilidade de cultivares com características que possibilitam a adequação destes materiais às diferentes regiões, observa-se, muitas vezes, produção baixa e irregular qualidade nutricional.

Tendo em vista que a adubação nitrogenada apresenta efeitos consideráveis quanto à produção, concentração de compostos nitrogenados e outros indicadores do valor nutritivo e qualidade da forragem, objetivou-se avaliar a resposta produtiva e a composição bromatológica do sorgo BR 601 em função da adubação nitrogenada.

\section{MATERIALE MÉTODOS}

O experimento foi executado na Estação Experimental do Instituto Nacional do Semiárido(INSA), no município de Campina Grande-PB, durante o período de março a julho de 2008. As variáveis climáticas estão apresentadas na tabela $\mathbf{I}$.
O delineamento experimental utilizado foi em blocos casualizados, com cinco repetições. Os tratamentos experimentais foram doses crescentes de adubação nitrogenada: $0,50,100,150$ e $200 \mathrm{~kg}$ de N/ha (sulfato de amônio) realizada em dose única, manualmente e em área total de cada parcela, quando a planta atingiu $30 \mathrm{~cm}$ de altura.

O sorgo utilizado foi o híbrido BR 601, com característica forrageira e porte alto $(3,00 \mathrm{~m})$. A semeadura da gramínea foi realizada manualmente em março de 2008, com densidade de 12 sementes por metro linear, em área não calcareada, em parcelas de $20 \mathrm{~m}^{2}$ (5,0 x 4,0 m), com 0,7 metros de espaçamento entre linhas, estabelecendo com o desbaste, 14 plantas por metro linear. $\mathrm{O}$ análise solo $(0-20 \mathrm{~cm})$ antes da adubação foi: $\mathrm{pH}$ ( $\left.\mathrm{H}_{2} \mathrm{O}\right)$ 5,8; P (extraído com solução mehlich1) $13,61 \mathrm{mg} / \mathrm{dm}^{3 ;} \mathrm{K}^{+} 167,50 \mathrm{mg} / \mathrm{dm}^{3} ; \mathrm{H}^{+}+\mathrm{Al}^{+3}$ $3,63 \mathrm{cmolc} / \mathrm{dm}^{3} ; \mathrm{Al}^{+3} 0,10 \mathrm{cmolc} / \mathrm{dm}^{3} ; \mathrm{Ca}^{+2}$ $2,10 \mathrm{cmolc} / \mathrm{dm}^{3} ; \mathrm{Mg}^{+2} 1,00 \mathrm{cmolc} / \mathrm{dm}^{3} ; \mathrm{Na}^{+}$ $0,81 \mathrm{cmolc} / \mathrm{dm}^{3}$; capacidade de troca de cátions 7,16; MO 8,62 g/kg (Estação Experimental do Instituto Nacional do Semiárido).

O sorgo foi colhido, aos 119 dias após o plantio, no estádio de grãos farináceos duros. O corte de avaliação foi feito manualmente com cutelos, tomando-se a linha central de cada parcela e eliminando-se um metro das extremidades como bordadura. $\mathrm{Na}$ avaliação foram considerados, portanto, a produção dos dois metros de sulco por parcela, procedendo-se inicialmente a contagem do número de plantas por metro linear. Todo o material contido na linha avaliada foi colhido rente ao solo, amarrado, identificado, e levados a casa de apoio para

Tabela I. Médias climáticas mensais (2008)*. (Monthly mean values for climate data (2008)).

\begin{tabular}{lcccccr}
\hline & Fevereiro & Março & Abril & Maio & Junho & Julho \\
\hline Precipitação $(\mathrm{mm})$ & 0,7 & 407,3 & 56,9 & 83,4 & 47,5 & 96,3 \\
Temperatura média $\left({ }^{\circ} \mathrm{C}\right)$ & 27,6 & 26,3 & 24,6 & 23,9 & 22,3 & 21,6
\end{tabular}

*Estação meteorológica do Instituto Nacional do Semiárido. 


\section{PRODUÇÃO E COMPOSIÇÃO DO SORGO SOB DOSES DE NITROGÊNIO}

pesagem e processamento do material.

Aproximadamente $500 \mathrm{~g}$ de cada fração foi seca a $65^{\circ} \mathrm{C}$ até atingir peso constante. A partir desses dados, foi estimado: a biomassa total de panícula, folhas, colmo e de material morto. Após secagem as amostras foram processadas a fim de se estimar material mineral (MM) pela metodologia de Weende, fibra em detergente neutro (FDN ( $\alpha$ amilase)) e fibra em detergente ácido (FDA) conforme técnicas descritas por Silva e Queiroz (2002), os teores de proteína bruta (PB) pelo método de Kjeldahl e hemicelulose pelo método de Van Soest (1994).

Os dados obtidos foram submetidos à análise de variância e regressão, utilizandose o programa SAEG (1999), tomando-se como critério para escolha dos modelos, os valores dos coeficientes de determinação e a significância dos parâmetros da regressão, testados pelo teste t, ao nível de $5 \%$ de significância.

\section{RESULTADOSEDISCUSSÃO}

A produção de matéria verde (PMV) obteve efeito quadrático $(\mathrm{p}<0,05)$ em resposta ao incremento da adubação nitrogenada (figura 1), com produção média variando de 22600 a $39000 \mathrm{~kg}$ de $\mathrm{MV} / \mathrm{ha}$. O ponto de máxima é obtido com 143,19 kg de $\mathrm{N} /$ ha com produção de $37996 \mathrm{~kg}$ de $\mathrm{MV} / \mathrm{ha}$. Esses resultados são superiores aos encontrados por Gomes et al. (2006), que avaliando, no estado do Ceará, o comportamento agronômico de onze genótipos de sorgo com adubação mineral NPK 60-40-30 (145 kg de N/ha), obtiveram rendimento médio de

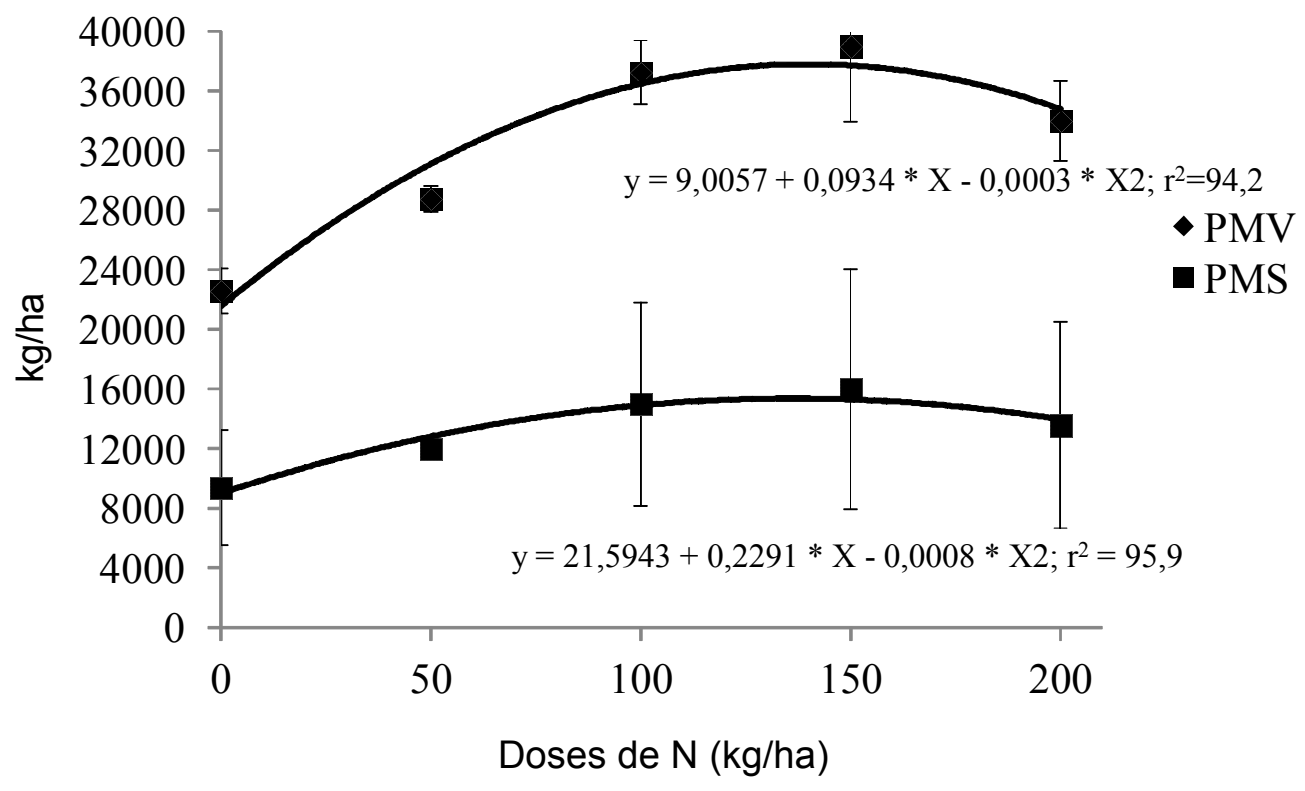

Figura 1. Produção de matéria verde (PMV) e seca (PMS) do híbrido de sorgo BR 601 em função de doses de adubação nitrogenada (as barras verticais representam o desvio padrão da média; cada ponto representa a media de 5 repetições). (Fresh (PMV) and dry matter (PMS) production of the BR 601 sorghum hybrid as a function of nitrogen levels. The vertical bars represent the mean standard deviation; each point represents the mean of five replicates). 
MACEDO, SANTOS, DA SILVA, DE ANDRADE, DA SILVA, DA SILVA E DE OLIVEIRA

$32173 \mathrm{~kg} \mathrm{MV} / \mathrm{ha}$, com destaque para o híbrido BR 601, o mesmo utilizado neste trabalho com produtividade de $33504 \mathrm{~kg}$ $\mathrm{MV} / \mathrm{ha}$, o que sugere que este genótipo apresenta características adaptáveis para as condições edafoclimáticas de estudo. Oliveira et al. (2005) trabalhando com quatro cultivares de sorgo e três níveis de adubação nitrogenada $(50,75$ e $100 \mathrm{~kg} / \mathrm{ha})$, observaram rendimentos de matéria natural com variação entre 45,87 a $67,56 \mathrm{t} / \mathrm{ha}$, evidenciando as potencialidades de produções do sorgo em condições adversas.

Na figura 1 observa-se também resposta quadrática $(\mathrm{p}<0,05)$ da produção de matéria seca (PMS) ao aumento do nível de adubação no solo, com produções variando de 9400 a $16000 \mathrm{~kg}$ de MS/ha. Em função dos níveis de adubação o ponto de máxima é obtido com $155,67 \mathrm{~kg}$ de N/ha com produção de 16275 $\mathrm{kg}$ de MS/ha. Estes resultados são superiores aos encontrados por Gomes et al. (2006) que obtiveram produção de $10860 \mathrm{~kg} \mathrm{MS/}$ ha para o híbrido BR 601. Entretanto, Oliveira et al. (2005) trabalhando com três híbridos (CMSXS 762, BRS 610 e BR 700) e uma variedade (BR 506), e doses de nitrogênio de 50,75 e $100 \mathrm{~kg} / \mathrm{ha}$, verificaram que as produ-ções de massa seca não diferiram entre as cultivares, oscilando de 14,22 t/ha a 16,38 t/ha. Não obstante, Rodrigues Filho et al. (2006) avaliando quatro híbridos de sorgo (CMSXS 762, BRS 610, BR 700 e BR $506)$ e três doses de nitrogênio (50, 75 e 100 $\mathrm{kg} / \mathrm{ha}$ ) constataram que as doses de nitrogênio não proporcionaram diferença nas produções de matéria natural e MS em t/ha, cujas médias foram de 59,32 e 15,17 t/ha, respectivamente.

Magalhães et al. (2010) avaliando 25 híbridos de sorgo de duplo propósito, sendo 22 híbridos novos, pertencentes ao programa de melhoramento genético de sorgo da Embrapa Milho e Sorgo, e três híbridos testemunhas (BR 601, BR700 e VOLUMAX), observaram PMS maior para o genótipo VOLUMAX (16,08 t/ha). O híbrido BR 601 apresentou produção média de 11,25 t/ha.
Resultados semelhantes aos valores citados foram encontrados por Pedreira et al. (2003) que, ao trabalharem com diferentes híbridos forrageiros, observaram PMS variando entre 16,03 a 10,8 t/ha.

Estes resultados destacam e reforçam a importância do híbrido BR 601 para regiões semiáridas, pois em comparação aos demais genótipos, este apresenta resposta satisfatória em produção, característica que pode estar associada à espécie que foi trabalhada sob condições edafoclimáticas favoráveis para o seu crescimento e desenvolvimento, levando em consideração que durante os meses que sucederam o plantio, a precipitação média mensal foi de $62,6 \mathrm{~mm}$. Vale destacar que o híbrido avaliado é considerado de porte alto, podendo atingir até $3 \mathrm{~m}$ de altura. As respostas obtidas neste estudo alimentam o ensejo de pesquisas em condições geográficas especificas no país buscando determinar o zoneamento ideal para cada híbrido em estudo.

Entre os componentes que formam a biomassa total da gramínea (figura 2), a produção de lâmina foliar e material morto não diferiu $(\mathrm{p}>0,05)$ entre os tratamentos, isto implica que o aumento positivo ocasionado na produção do sorgo não se deve à contribuição destes dois componentes da planta.

$\mathrm{Na}$ análise dos demais constituintes da planta, verificou-se que o percentual de colmo na planta diminuiu de forma quadrática ao incremento da adubação nitrogenada, sendo o ponto de mínimo atingido com 142,5 $\mathrm{kg} \mathrm{N} /$ ha com $46,51 \%$ de colmo na planta. No entanto, o componente panícula obteve resposta quadrática contrária, atingindo o ponto de máxima, com $45,04 \%$, na dosagem de $142,25 \mathrm{~kg}$ de N/ha, o que explica que este componente foi o principal constituinte da planta e, portanto, o principal responsável pelo aumento na PMS (figura 2). De acordo com Gontijo Neto et al. (2004), o aumento nos níveis de adubação proporcionaram maiores produções de panículas, refletindo na diminuição da relação colmo + folha/ 


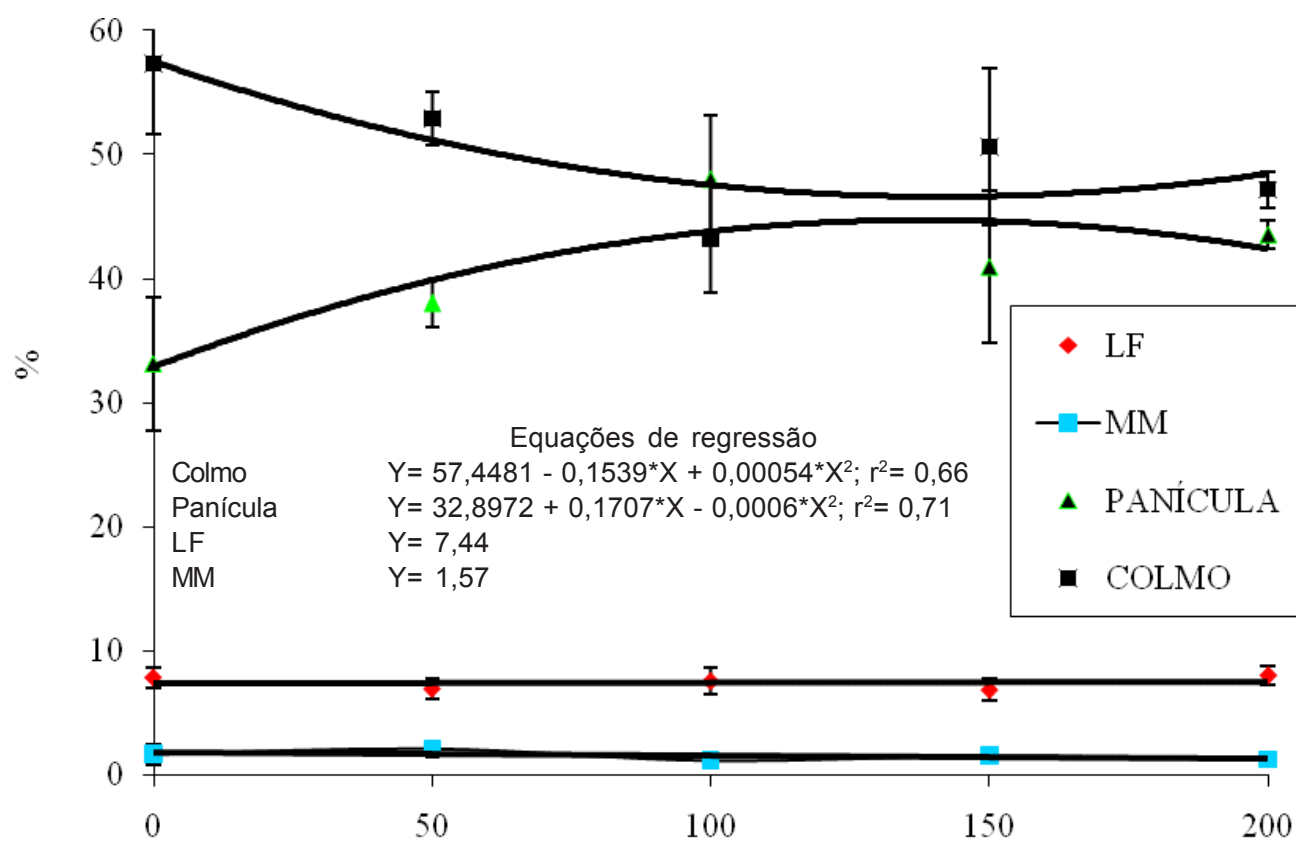

Doses de $\mathrm{N}(\mathrm{kg} / \mathrm{ha})$

Figura 2. Percentuais de matéria seca de lâmina foliar, colmo, panícula e material morto em relação à matéria seca total da planta de sorgo. As barras verticais representam o desvio padrão da média (as barras verticais representam o desvio padrão da média; cada ponto representa a media de 5 repetições). (Percentage of dry matter in leaf lamina, stem, panicle and death material, in relation with total dry matter of sorghum plant. The vertical bars represent the mean standard deviation; each point represents the mean of five replicates).

panícula, na maior proporção de panículas e no teor de MS da planta inteira

Verifica-se na tabela II que os teores

médios de matéria seca (MS), e proteína bruta $(\mathrm{PB})$ responderam de forma linear crescente $(p<0,05)$ ao incremento da

Tabela II. Teores médios de matéria seca, matéria mineral (MM) e proteina bruta (PB) da planta, e equações de regressão em função de doses de nitrogênio (X). (Plant mean contents of dry matter (MS), mineral matter (MM), and crude protein (PB), and regression equations as a function of nitrogen levels $(X)$ ).

\begin{tabular}{|c|c|c|c|c|c|c|c|c|}
\hline & \multicolumn{5}{|c|}{ Níveis de adubação nitrogenada } & \multirow[t]{2}{*}{ CV } & \multicolumn{2}{|c|}{ Equações de regressão } \\
\hline & 0 & 50 & 100 & 150 & 200 & & & \\
\hline MS (\%) & 34,84 & 37,89 & 38,88 & 38,42 & 38,98 & 5,35 & $Y=36,0412+0,0176 * X$ & $r^{2}=0,66$ \\
\hline MM (\% MS) & 6,41 & 6,01 & 5,84 & 5,42 & 5,39 & 13,57 & $Y=6,3416-0,0053{ }^{*} X$ & $r^{2}=0,95$ \\
\hline PB (\%MS) & 4,99 & 4,73 & 5,51 & 5,65 & 6,23 & 14,13 & $Y=4,7456+0,0068 * X$ & $r^{2}=0,84$ \\
\hline
\end{tabular}

${ }^{1} \mathrm{~kg} / \mathrm{ha}$; CV= coeficiente de variação $(\%) ; r^{2}=$ coeficiente de determinação. 
adubação nitrogenada, entretanto, resposta contrária $(\mathrm{p}<0,05)$ foi observada para MM.

O percentual médio de MS da planta variou de $34,84 \%$ no tratamento controle a $38,98 \%$ no tratamento com $200 \mathrm{~kg}$ de N/ha, resultando em acúmulo de $11,88 \%$. Demarchi et al. (1995) ressaltam que no processo de maturação, do florescimento ao estádio de grãos duros, ocorrem alterações na composição química da planta, principalmente pela redução dos teores de PB e DIVMS das partes vegetativas colmo e folhas. Entretanto, a produção de nutrientes aumenta acentuadamente, principalmente em materiais genéticos de maior produção de grãos, em função da elevada translocação de nutrientes para a panícula. Não obstante, o aumento na participação da panícula na estrutura física da planta sugere ser o principal responsável pela alteração no teor de MS (figura 2).

Estes resultados são superiores aos encontrados por Pesce et al. (2000) que trabalhando com vinte genótipos de sorgo obtiveram percentual de matéria seca de $25,8 \%$ para o híbrido BR 601 . Esta redução no percentual de matéria seca descrita pelos autores pode estar associada ao período de maturidade da planta, as quais foram colhidas em estádio de grão pastoso. Molina et al. (2000) recomendam que o material para ser colhido deve apresentar de 30 a $35 \%$ de matéria seca. Entretanto o aumento da MS observada no experimento em função da adubação nitrogenada deve estar em função do aumento no teor de matéria seca da panícula (figura 2). De acordo com Gontijo Neto et al. (2004), o aumento nos níveis de adubação proporcionou maior produção de panículas, refletindo na diminuição da relação colmo + folha/panícula, na maior proporção de panículas e no teor de MS da planta inteira. Oliveira et al. (2005) avaliando as características agronômicas de quatro cultivares de sorgo forrageiro observaram que o teor de matéria seca variou de 22,86 a $31,51 \%$.

$\mathrm{O}$ teor de PB foi incrementado linear- mente com o aumento nas doses de adubo aplicadas, com variação no teor protéico de 4,99 a $6,23 \%$, respectivamente para os tratamentos 0 e $200 \mathrm{~kg}$ de N/ha. Estes resultados são superiores aos encontrados por Gomes et al. (2006) que avaliando o comportamento agronômico e alguns constituintes químico-bromatológicos das cultivares de sorgo forrageiro (Sorghum bicolor, L. Moench) BR 700, VOLUMAX, SHS 500, MASSA 03, BRS 701,0698005, AG2005,BRS506,0698007, BR 601 e IPA 467-4-2 encontraram média de PB de 5,24\%, apresentando o híbrido BR 601 teor protéico de $4,89 \%$. Segundo os autores, a panícula foi a fração de maior teor de hemicelulose e PB e menor teor de FDA, caracterizando-se como a porção da planta de maior valor nutritivo. Assim, sugere-se que o aumento no teor de PB encontrado neste estudo pode estar em função ao aumento no percentual de matéria seca de panícula na planta (figura 2).

Observa-se na tabela III que os teores de fibra em detergente neutro (FDN), fibra em detergente ácido (FDA) e hemicelulose do material não diferiram ( $p>0,05)$ em função da adubação nitrogenada.

Tanto o teor de FDA quanto o de FDN são negativamente correlacionados com a digestibilidade e com o seu consumo, respectivamente (Van Soest, 1994). Desta forma, sugerem-se maiores taxas de consumo voluntário de silagens de híbridos de sorgo que apresentem menos concentração de FDN. Apesar de não significativo, a FDN e FDA apresentam valores médios de 68,60\% e $51,99 \%$, respectivamente. Estes resultados são superiores ao encontrados por outros autores (Pesce et al., 2000; Gomes et al., 2006) avaliando o mesmo híbrido de estudo. Entretanto, o teor médio de hemicelulose (10,71\%) foi inferior ao encontrado pelos mesmos autores.

Apesar do baixo nível de precipitação pluviométrica durante o período experimental, estes resultados sugerem que o híbrido BR 601 responde de forma satisfatória às dosagens de nitrogênio no solo, com eleva- 
PRODUÇÃO E COMPOSIÇÃO DO SORGO SOB DOSES DE NITROGÊNIO

Tabela III. Teores médios de fibra em detergente neutro ( $F D N$ ), fibra em detergente ácido (FDA) e hemicelulose, e equações de regressão em função de doses de nitrogênio $(X)$. (Plant mean contents of neutral detergent fiber (FDN), acid detergent fiber (FDA) and hemicellulose, and regression equations as a function of nitrogen levels $(\mathrm{X})$ ).

\begin{tabular}{|c|c|c|c|c|c|c|c|}
\hline & \multicolumn{5}{|c|}{ Níveis de adubação nitrogenada (kg/ha) } & \multirow[t]{2}{*}{$\mathrm{CV}$} & \multirow[t]{2}{*}{ Equações de regressão } \\
\hline & 0 & 50 & 100 & 150 & 200 & & \\
\hline FDN $(\%)$ & 67,36 & 71,48 & 69,21 & 67,65 & 67,32 & 5,37 & $Y=68,60$ \\
\hline FDA (\%) & 49,84 & 53,27 & 51,51 & 52,90 & 51,96 & 5,16 & $Y=51,89$ \\
\hline Hemicelulose & 17,52 & 18,21 & 17,70 & 14,75 & 15,37 & 20,34 & $Y=16,71$ \\
\hline
\end{tabular}

$C V=$ coeficiente de variação (\%).

da produção de matéria seca e aumento nos níveis de proteína da planta, entretanto, sem alterar os constituintes fibrosos da planta, sugerindo o aumento no valor nutritivo da silagem e aceitabilidade no consumo voluntário pelos animais.

$\mathrm{Na}$ fenofase de grãos farináceos duros, não se constatou efeito significativo da

\section{BIBLIOGRAFIA}

Demarchi, J.J.A.A., Boin, C. e Braun, G. 1995. A cultura do sorgo (Sorghum bicolor L. Moench) para produção de silagens de alta qualidade. Rev Zootecn Nova Odessa, 33: 111-136.

Gomes, S.A., Pitombeira, J.B. e Neiva, J.N.M. 2006. Comportamento agronômico e composição químico-bromatológico de cultivares de sorgo forrageiro no Estado do Ceará. Rev Ciên Agronôm, 37: 221-227.

Gontijo Neto, M.M., Obeid, J.A. e Pereira, O.G. 2004. Híbridos de Sorgo (Sorghum bicolor (L) Moench) cultivados sob níveis crescentes de adubação. Características agronômicas, carboidratos solúveis e estruturais da planta. Rev Bras Zootecn, 33: 1975-1984.

IBGE. 2007. Diretoria de Pesquisas, Coordenação de Agropecuária, Pesquisa da Pecuária Municipal 2007. http://www.ibge.gov.br/home/ estatistica/economia/ppm/2007/comentarios. pdf

Magalhães, R.T., Gonçalves, L.C., Borges, I., Rodrigues, J.A.S. e Fonseca, J.F. 2010. Produção e composição bromatológica de vinte e cinco genótipos de sorgo (Sorghum bicolor (L.) adubação nitrogenada sobre o acúmulo de matéria seca foliar, nem sobre a quantidade de material morto. Entretanto, o percentual de colmo tende a diminuir com a dose de nitrogênio, enquanto panícula aumenta.

Os teores de MS e PB tendem a aumentar com a dose de nitrogênio, sem, no entanto alterar os teores de FDN, FDA e hemicelulose.

Moench). Arq Bras Med Vet Zoo, 62: 747-751. Molina, L.R., Gonçalves, L.C., Rodriguez, N.M., Rodrigues, J.A.S., Ferreira, J.J. e Ferreira, V.C.P. 2000. Avaliação agronômica de seis híbridos de sorgo (Sorghum bicolor (L.) Moench). Arq Bras Med Vet Zoo, 52: 385-390.

Oliveira, R. de P., França, A. F. de S. e Filho, O.R. 2005. Características agronômicas de cultivares de sorgo (Sorghum bicolor (L.) Moench) sob três doses de nitrogênio. Pesqui Agropecu Trop, 35: 45-53.

Pedreira, M.S., Reis, R.A., Berchielli, T.T., Moreira, A.L. e Coan, R.M. 2003. Características agrônomicas e composição química de oito híbridos de sorgo (Sorghum bicolor (L.) Moench). Rev Bras Zootecn, 32: 1083-1092.

Pesce, D.M.C., Gonçalves, L.C.e Rodrigues, J.A.S. 2000. Análise de vinte genótipos de sorgo (Sorghum bicolor (L.) Moench), de portes médio e alto, pertencentes ao ensaio nacional. Rev Bras Zootecn, 29: 978-987.

Rodrigues Filho, O., França, A.F.S., Oliveira, R.P., Oliveira, E.R., Rosa, B., Soares, T.V. e Mello, S.Q.S. 2006. Produção e composição bromato- 


\section{MACEDO, SANTOS, DA SILVA, DE ANDRADE, DA SILVA, DA SILVA E DE OLIVEIRA}

lógica de quatro híbridos de sorgo forrageiro (Sorghum bicolor (L.) Moench) submetidos a três doses de nitrogênio. Ciên Anim Bras, 7: 37-48.

SAEG. 2007. Sistema para Análises Estatísticas. Versão 9.1. Fundação Arthur Bernardes. UFV. Viçosa.
Silva, D.J. e Queiroz, A.C. 2002. Análise de alimentos: métodos químicos e biológicos. $3^{\mathrm{a}}$ ed. UFV. Viçosa.

Van Soest, P.J. 1994. Nutritional ecology of the ruminant. $2^{\mathrm{a}}$ ed. Cornell University Press. Ithaca. $476 \mathrm{pp}$.

Archivos de zootecnia vol. 61, núm. 234, p. 216. 